Southwest Philosophy Review, 1995

$T$ his paper was originally presented at a $C$ onference (the 0 ntological and Practical) held at the $U$ niversity of $T$ exas at $A$ ustin, part of a celebration of the career of $D$ oug $B$ rowning. It was subsequently published in a special issue of the S outhwest Philosophy R eview. H oward C urzer commented on the paper.

\title{
THE VALUE OF PASSIONS IN PLATO AND ARISTOTLE
}

\author{
Stephen Leighton
}

\section{Prologue}

The celebration of Doug as a philosopher and a person would be incomplete without some discussion of Aristotle. Like most good philosophers, Doug looks back to the tradition that precedes him, seeking insights, interesting ideas and profound mistakes. But Doug's interest does not end there, especially where Aristotle is concerned. The wonder and joy he takes in trying to determine what Aristotle might say about a matter, how Aristotle's thought coheres, what might have occasioned a particular book in the Metaphysics... will be apparent to most of us here today. To have shared in this activity and all the enthusiasm that Doug brings to it has been a wonderful part of my life. I am immeasurably grateful.

\section{Introduction}

We are neither praised nor blamed in so far as we have feelings (ta pathē); for we 
do not praise the angry or the frightened person, and do not blame the person who is simply angry, but only the person who is angry in a particular way. ${ }^{1}$

On the whole, Plato seems not to have agreed. In his Phaedo, for example, Socrates speaks of desire imprisoning the soul to the body, of keeping away from pleasures and desires as far as one can, of violent pleasure or pain or passion creating the most extreme evils for oneself, of every pleasure and pain providing another nail to rivet the soul to the body (82E-83D).

In what follows I consider their disagreement about the value of passions. In so doing I hope to explicate that, and the ways that, these competing evaluations are fostered by their respective philosophical psychologies, particularly their analyses of the passions and the intellect.

Some caveats before beginning. Since our concern is for underlying themes, connected in certain ways, what we can discern will be but a part of a larger explanation of these matters. ${ }^{2}$ Moreover, because of the very broad scope of this study, we should not expect to explicate or even accommodate everything relevant that our thinkers say, Indeed, it should be noted, particularly with regard to Plato, that I am reflecting on but one strand, within the web of his thought. ${ }^{3}$

I begin with the competing evaluations, then turn to underlying psychologies.

\section{Contrasting Evaluations of Passions:}

If we focus on some of the more central texts in Plato's middle period, here the Phaedo and Republic, we find some quite striking thoughts about the passions. For Plato (1) certain passions are to be turned away from or eliminated if (and as far as) possible (e.g. fears and wild lusts, phōbon kai agriōn erōtōn). ${ }^{4}$ Moreover, (2) with respect to those passions not or not to be turned from or eliminated, many deserve severe restriction and limitation (e.g. the pleasures of food, drink, sex, laughter, sexual frenzy, grief, indignation, pity, womanish emotions). ${ }^{5}$ Generally, the more the passions are limited the better; the passions are disdained (64D-E, atimazein); the place they do have seems warranted only through their support of our existence. ${ }^{6}$ It is a (3) dispassionate rather 
than passionate self that is our goal (cf. Phaedo 84A-B). Where passion does enter, this dark horse requires (4) intellect's mastery, control, reigning in, disciplining. ${ }^{7}$

Passion is thought to have two roles in the lives of those who act well. One sort of "virtue" is the mastering of certain pleasures by others, an exchange of pleasures for pleasures, pains for pains, fears for fears. For example, through a fear of death, cowardice and other evils are often avoided (Phaedo 68B-69B). Real or true virtue (5), however, involves wisdom's control rather than the exchanges of passion. The aim is not being excited over one's desires (tas epithumias), but being scornful of them and well ordered (oligōōos echein kai kosmiōs, Phaedo 68C). ${ }^{8}$

By contrast, Aristotle displays no tendency to turn from or eliminate the passions (contra 1). The simple fact of passion is itself ethically neutral. ${ }^{9}$ One is to feel the passions in the right fashion, where that has to do with their correct deployment and employment (N.E. 1106B 15-24), rather than their severe restriction and limitation (contra 2). ${ }^{10}$ Being passionate comes to be central to living well; a passionate rather than the dispassionate self becomes the human ideal (contra 3)-an ideal which allows for and endorses strong, even violent, passion. ${ }^{11}$ And rather than a focus on the control of emotion by mastery, disciplining, reigning in, by intellect or intellect abetted, passions themselves, through the habituation of character, are thought of as independent and revealing responses to situations (contra 4$){ }^{12}$

Concerning virtue while Aristotle can recognize the roles Plato assigns to passion in the lives of those who act well, his own analysis would understand virtue as conceived by Plato to be mere continence (contra 5). Virtue for Aristotle is neither a matter of the exchange of passions, nor intellect controlling passion, nor even a treating of passion with disdain, but centers on a habituated character in which a passionate response aptly responds to its situation.

\section{Preliminary Conjectures:}

I suggest that what lies behind the Platonic model is a conception of passion and intellect as relatively independent and structurally opposed components locked in 
struggle. Because passions are either simply disruptive or are disposed to be so, intellect must defeat them.

I also suggest that Aristotle offers a quite different model. Aristotle does indeed contrast passion and the intellect, but he seems to integrate them, no longer conceiving them as antagonistic or even independent forces. This integration one sees in the wellformed character; its activity is understood on a model more akin to how we think of the responsive activities of a creative musician or skilled athlete. Intellect's battle with and hoped-for victory over passion becomes unnecessary; herein Aristotle seems to diminish or even relinquish the desirability of a deliberating control and dominance by intellect. ${ }^{13}$ Thus while Plato features thought needing to oppose and control passion, Aristotle features the passions as appropriate, reliable, and insightful responses to our situations. Our emotions come to find their own place, to have their own insights.

Can this be shown to be more than matters of conjecture?

\section{The Psychology of the Phaedo}

In the Phaedo Plato focuses his attention on a soul-body contrast. This is relevant to our concern inasmuch as the intellect is attributed to the soul, whereas the pleasures of food, drink, sex, fears, generally the passions, are phenomena of the body (64D- E). The self seems to be our intellect; it is this that we, like Socrates, can hope shall survive our earthly demise, attaining the greatest of blessings (63E). ${ }^{14}$ In the meanwhile our body imprisons the soul (82E ff.), serves to confuse us (66D), to fill "us with wants, desires, fears, all sorts of illusions and much nonsense..."(66C) Our passions are a powerful force within our enmattered self. Because of their tie to the body rather than the soul, they are conceived to be distinct and hereby separate from the intellect. ${ }^{15}$ Body and soul are two realms, two levels of reality, which are together for a time but come to separate. In consequence, passions are viewed as other than, independent of, unharnessed and uncontrolled by intellect. Through their lineage to the body, passions serve to disrupt, confuse, cause fear, and interfere with the intellect, the self(cf. 65-7). ${ }^{16}$ And so the philosopher comes to disdain the passions but to the extent they are necessary (64D). 
For one who has lived as a philosopher, death can be freedom from them and their interfering ways ( $8 \mathrm{lE}$ ff.). Then, but only then, can intellect operate fully (66E). In the meantime, living well depends on turning away from, shunning, fleeing from, escaping, taking leave of, not contacting or associating with the body and its passions (64E, 65C-D, 66D, 80D-8IB). In so doing the philosopher achieves the catharsis sought; the influence of the passions is both excluded and limited (67C, cf. 8IA-B). ${ }^{17}$

What seems crucial to the above account is that the distinction between the soul and the bodily is understood as a separation and a reification with empirical consequence. That is, not only are soul and body distinct, but separable and come to be separate. So similarly, the interesting attributes of each, intellect and passion.

Further, the prying apart of soul and body, intellect and passion by the distinction and thereby separation is oppositional in conception. The nature and thereby principles of operation of each are excluded from the other, without features in common. Features of the soul are of one sort and belong to it and only it; features of the bodily are quite different and belong to it and only it. ${ }^{18}$ The relationship between body and soul, intellect and passion, thereby is without common ground and is reduced to one turning away from the other or to warfare in which the attempt is to master the other through elimination, limitation and suppression. Successful relationships become those of victory. Desirable victory is displayed in virtue by means of intellect's control of the passions, in disdain for the passions.

Here viewing the relationship between our self and our bodily operations as a distinction that is separation-and a separation of radically different sorts-has yielded a striking understanding of the passions and their relationship to the self, leaving Plato with a very negative view of our passions. ${ }^{19}$

\section{The Psychology of the Republic}

The goals and arguments of the Republic are considerably different. The famous and perplexing distinctions between reason, spirit, and desire (436ft) is a distinction 
within the soul rather than a soul-body contrast. Moreover, the primacy given to the intellect is softened a) in the sense that any conception of self seems not to be located in the intellect or in any other single part but in the operating tripartite soul, b) in the sense that intellect's success needs spirit's assistance, and c) in the sense that the character of the person becomes a focus. ${ }^{20}$ Furthermore the distinctions within the soul aren't obviously seen as separations or contrasts between empirical components. We have, then, reason to be optimistic that the Republic's psychology can allow a more favorable understanding of the connections between passion and intellect.

To some extent our optimism is rewarded. For example, locating the passions within the soul and also the self means that while death remains the separation of body and soul, that separation no longer can be a freeing from the passions. Thus our passions are deeply integrated within the self and thereby less easily dismissed. This, together with the placement of character, means that the Phaedo's antipathies regarding the passions are less readily at hand. Further, the functional thinking of the Republic (352D ft) together with the inclusion of the passions within the soul and self, makes it seem that whichever part of the soul they fall under, ${ }^{21}$ they must have a legitimate function. Now the passions-especially those associated with the spirited part of the soul--can come to have a more positive analysis. For example, Plato's conception of certain virtues gives a place to passions such as fear, and does so without disdain. ${ }^{22}$

While the Republic does offer more generous remarks about particular passions, much remains familiar - especially in the psychological explanation offered, and what it enables. The reported attitude of Sophocles towards sex in old age (namely being glad to have escaped this, like a slave who has escaped from a mad and cruel master (cf. 329C)) pervades much of the Republic's attitude towards passions. And in some ways these attitudes are more deeply entrenched.

In the Republic an understanding of the self involves components. Within the componentist self, the components of the soul are conceived of as parts, discrete and independently functioning entities. Indeed to count as a soul part is for each part to do its own task, something that only it does or does best-where this is understood as a matter of 
division by per se exclusion from other parts. ${ }^{23}$ Distinctions may not here yield empirical separations as it has done in the Phaedo, but they do yield radical contrasts of type and nature. Because of this way of conceptualization, the important properties of each part cannot be attributed elsewhere-lest the original divisions collapse. ${ }^{24}$ Soul parts are autonomous units. Plato can't (and generally doesn't) borrow from a part's function to explain either another part's operation or the interrelationship amongst parts. ${ }^{25}$

Thus while it is apparent that the parts are to interrelate, how they do so is opaque - as is any account of a unified self through this diversity. In consequence, talk of their relationships becomes highly metaphorical. Desire lacks significant features in common with intellect and vice versa. Each is left to master or overpower the other-only now spirit too joins the fray. ${ }^{26}$ The Phaedo's battle between soul and body has been relocated but rages on. Because it is bereft of intellect's properties, desire has much the value it had in the Phaedo. Indeed the most worrying danger to the self remains the danger of desire. ${ }^{27}$

The psychological model has undergone change but the underlying approach and impact remains. It is a part psychology. The parts are distinct, thereby separate and wholly different in identity, nature and function from the other parts (faculties). In these terms intellect must master and battle passion. And thus the account of many of the virtues reflects the same.

The valuation of passion and its position with respect to intellect is much the same. Elimination is restricted but still desirable (1); limitation remains (2), again in terms of mastering, holding in line (4). Success in living is seen in the prominence of the dispassionate intellect (3). Such success brings a sense of unity within the diversity that is the self-though without explanation beyond victory or mastery.

\section{Aristotle's Psychology}

Aristotle's psychological model differs greatly. The differences significant to our issue include:

i) a rejection of Plato's part psychology;

ii) a reasonably clear understanding of the non-empirical nature of the soul's analysis 
(distinction doesn't require separation);

iii) a concern for unity within the diversity of the soul;

iv) a hierarchical (rather than oppositional) ordering within the soul;

v) a consequent understanding of the lower levels in terms of their higher levels in the case of complex life forms;

vi) a consequent intellect passion distinction without a intellect passion separation or split.

As a result of this psychology, I contend that Aristotle is able:

vii) to integrate the passions into the self in a way that Plato was not, having dispelled some of the oppositions that Plato's thought seems dominated by. That integration facilitates the differences in evaluation.

For Aristotle the question of the soul is the question of life (410B19-27, 412AI2$15,413 \mathrm{~A} 20, \mathrm{~B} 1)$, life in its various complexities. ${ }^{28}$ Aristotle approaches the soul and its capacities in terms of his doctrine of causation; the soul being 'the form of a natural body which has life potentially' (De An 412AI8-19). By approaching the matter in this way, Aristotle adopts a model of explanation that seeks distinctions but belies Plato's commitment to empirical or quasi-empirical units (separations) (ii). For just as one pursues the matter mistakenly if one looks for the form of a statue as if it were some other thing separate or separable, about, or in (non-technical) the relevant body, so one pursues the matter mistakenly by looking for the soul as if it were some thing separate or separable from the body. ${ }^{29}$ Body and soul are one as wax and its impression are one, as the matter of each thing and that of which it is matter are one. According to Aristotle, this is to be one in the most proper sense, actuality (412B4-10).

Significantly, this understanding of the relation between soul and body is also found in Aristotle's understanding of differences within the soul. Aristotle puzzles over how to understand the parts of the soul. He comments:

We have said, e.g., that one [part] of the soul is nonrational, while one has reason. Are these distinguished as parts of a body and everything divisible into parts are? Or are they two only in account, and inseparable by nature, as the convex and concave 
are in a surface? (N.E. 1102A28-31)

Aristotle goes on to suggest (misleadingly, I believe) that the answer doesn't matter here, but the position he takes is the latter. His divisions are not part separations but differences in account and inseparable by nature. ${ }^{30}$

Again, in De An Aristotle raises the question of soul parts (432a22). The background 'to this discussion seems to be a Platonic conception of things, a tripartite soul in particular. Aristotle's expresses no concern for whether we use the language of parts when speaking of the soul, but whether we 'are to posit separate parts of the soul.' (432B2) His view seems to be that while the distinctions must be respected, there is no need to think of this in terms of separations. Consider his thoughts on desire.

In addition to these there is the part concerned with desire, which would seem to be different from all both in definition and in potentiality. And it would be absurd surely to split this up; for in the part concerned with reasoning there will be wishing, and in the irrational part wanting and passion; and if the soul is tripartite there will be desire in each. (432B 1-6)

Aristotle has drawn our attention to the consequences of the Platonic separation analysis, finding them absurd. ${ }^{31}$ The language of parts can remain but the analysis of the soul has changed. Thus he can comment:

But it is clear from these things that the remaining parts of the soul are not separable, as some say; although that they are different in definition is clear. For being able to perceive and being able to believe are different, since perceiving too is different from believing; and likewise with each of the other parts which have been mentioned. (De An 413B27-32, cf. 411B528, 413A3-10)

Because Aristotle concerns himself with significant distinctions paramount in our explanations without commitment to empirical separations or quasi-empirical units (ii), the Platonic psychology of soul-parts, discrete, autonomous functioning units is thereby unfitting (i). Distinctions here do not entail empirical or quasi- empirical entities to be discrete, separate or autonomous. Interestingly, the ancient generally associated with empiricism has not been the empiricist that the ancient associated with rationalism has. 
Aristotle, then, must radically re-conceive the relation between passion and intellect, and much else as well. Part of that re-conception manifests itself in Aristotle's thought that a judgment can't be made on the basis of diversity simply; some unity is required (iii, cf. De An 3/2). Aristotle sees that battling or even harmonious components cannot explain what must be explained-unity within the self, as we might say. The Platonic analysis by difference of nature is deemed insufficient for these purposes and abandoned. ${ }^{32}$

Aristotle's basis for re-conception, I believe, is to be seen in his hierarchical understanding of the soul (iv). We have seen that for Aristotle the question of the soul is the question of life. Aristotle's understanding begins at the most basic form of life (plants), moving through more and more complex forms (animals in general, then the human animal). ${ }^{33}$ Commentators speak of the nutritive, sense-perceptive and rational soul (faculty, potentiality, cf. 415A15 ff., 432B24 ff.). The higher levels require and are supported by the lower but not vice versa. (No thinking without nutrition, but nutrition without thought cf. 413A30-33, 425A13 ff., 434A22 ff.).

Two things about this should interest us. First, the principle of analysis within the soul by complexity of life forms replaces the principle of exclusivity and oppositional natures. ${ }^{34}$ This in combination with the non-empirical nature of the enterprise means that the Platonic model of utterly different units in battle or harmony is not invoked.

Second, that and the way that the higher levels affect the analyses of the lower (v), better enables Aristotle to explain unity within the soul (iii). In creatures with an array of levels of souls (us, for example), one doesn't comprehend a lower soul simply by an appeal to the general analysis of that soul. Rather the understanding of a lower soul is in terms of its higher souls (v). ${ }^{35}$ For example, we and plants have a sexual-nutritive soul. And one can say a number of things in common about the teleology of each, their contribution to survival, and so forth. Yet a detailed understanding of said soul for a life form such as ours is more complex. Our sexual and nutritional activity is not understood adequately by an appeal to the analysis fitting a plant's soul, but incorporates our higher souls. Hence for us, but not our daffodils, we speak of the erotic, the delicious, fantasy, 
and so forth. Where there are higher souls, the lower level's analysis is infused with the higher.

Now a Platonic way of thinking need not be unsympathetic to these contrasts, but its way of understanding them would concern two different, diverse, and independent parts which somehow interact. Aristotle is without said part psychology (i). And whereas Plato has separated units, and difficulty explaining any relation between them (the unity problem that Aristotle raises), Aristotle's approach means to avoid such difficulties. It isn't that our reasoning affects our sexuality (though that can be true too), but that our sexuality involves reason, is structured by it (iv). Therein unity is preserved (iii). The rational soul helps inform our nutritive-reproductive soul rather than operates upon or in conjunction with it. Hence in an understanding of our sexual or nutritive activity, the place of intellect must figure prominently, not as an external force acting upon our sexual practices but within those sexual and nutritive practices (v). It is to be understood as facets of the analysis of some one thing (for example, as form and matter). ${ }^{36}$

\section{Aristotle's Account of the Passions}

All this has application to the relations between intellect and passion (vi). As a phenomena of desire (orexis), passion (pathos) is a feature of the sensory soul (cf. 414B 1-2, 413B24- 25). In light of the hierarchical ordering of the soul, Aristotle's understanding of our passions (as opposed to those of our dog' s) involves bringing the rational soul into that account-again not as some sort of external force that operates upon and reacts against it (though it may have that role too), but as inherent within the structure of our passions. Passion can be said to share in, to listen to intellect (cf. 11O2B13-03A3). Thereby Aristotle's analysis of the soul offers a view of passions in which they are themselves of rational heritage and structure without thereby stripping them from being passions. ${ }^{37}$ Here there can be no intellect passion split, no entities of utterly different nature, locked in struggle.

\section{Aristotle's Evaluation of the Passions}


Given this sort of psychological model, Plato's opposition between intellect and passion disappears. To understand passion requires talk of intellect, but not as some different thing that operates upon a basic, separate force of an opposite nature. Intellect cannot be understood as passions' police, a separate force that somehow keeps things in line. ${ }^{38}$ The guidance of passion does invoke the rational soul but as a phenomenon of passion rather than something external (contra 5). Because we don't have two different and oppositional things, thinking about how the two separate parts or two things, utterly diverse in nature, interact disappears as a concern. There is no general problem of bringing one into the analysis of the other, of unity within the self, and no need for principles external to explain the interrelationship of parts. Because of this Plato's tendency to see passion as a thing structurally opposed to intellect is gone. Because the structural opposition disappears, the impetus for the contrasting evaluations goes too. Thus much of the impetus for either eliminating (1) or severely restricting and limiting passion is removed (2). At the same time, the model of one thing controlling, mastering, reigning in, another becomes unnecessary (contra 4).

For Plato because the intellect and passion were distinct, separate entities operating with utterly different nature and principles, the deserved praise of intellect required a failure in passion. Thereby it was easy enough for Plato to come to the evaluative analysis he did. With the Aristotelian analysis, any praise for intellect doesn't reveal a lack in passion. And while it remains open to an Aristotelian to condemn passions, the psychological motivation driving that condemnation is removed. If anything, the psychology would motivate praise for passion (vii). Given all this, other Platonic themes start to become unnecessary for Aristotle. There is no longer prima facie suspicion of the passions on the basis of their distinctive and non-rational nature. Thereby the dispassionate self becomes unneeded (contra 3), and a passionate self becomes a perfectly plausible model. ${ }^{39}$ And because the elimination (I) and limitation (2) of the passions is not required, Aristotle is more able to take advantage of his teleology and functionalism to look for the contributions passions can, do and should make, rather than concern himself with their mastery, limitation and elimination (contra 4). In view of this, 
true virtue can't be seen as intellect over passion (5), but involving passion rightly developed.

So, then, changes in philosophical psychology have brought about changes in moral evaluation. While I am not suggesting the moral attitudes to the passions follow by a logical necessity from the psychological model, I am suggesting that they .are greatly facilitated. Many Platonic claims are less necessary and not adopted because of this different way of conceptualizing the relationship between intellect and passion. And this, in turn, allows Aristotle to turn to his teleology, looking for passions' insights.

\section{Stephen Leighton}

Queen's University, Canada

\section{Notes}

1 Aristotle Nicomachean Ethics, 1105B32-06A1, translation by T. Irwin (Hackett Publishing Company, 1985). Hereafter all references to works of Aristotle use conventional abbreviations. Translations of the N.E. by Irwin; translations of the De An by D.W. Hamlyn as found in A New Aristotle Reader, edited by J.L. Ackrill (Princeton University Press, 1987); translations of the Phaedo by G.M.A. Grube, (Hackett Publishing Company, 1981); translations of the Republic also by Grube (Hackett Publishing Company, 1974).

2 In looking for the ethical's dependency on the psychological, I am reversing the order of dependency often considered, cf. S. Hampshire's Innocence and Experience (Harvard University Press, 1989) and B. Williams' Shame and Necessity (University of California Press, 1993). I do not doubt the legitimacy of such approaches, but only suggest that the present approach is valuable too.

3 Roughly speaking, I take Aristotle to adhere to the evaluative view above expressed, though certainly particular remarks go in diverse ways. (See, for example, his thoughts about fear in courage, which seem to head in many different directions.) His psychological analysis is 
somewhat variegated-as we shall see. The valuation of the passions by Plato which most sharply contrasts Aristotle's is found in the Protagoras, Phaedo, and Republic. Plato does appear to offer a more friendly view of the passions in works such as the Symposium and Lysis — and even the preceding works have their friendly moments. (How different an approach the latter dialogues offer is open to dispute; and, following G. Santas's reflections on love in Plato and Freud: Two Theories of Love (Basil Blackwell, 1988), I think that where Plato is more amenable to the passions it is because his analysis of them strips them of their passionate nature.) With regard to changes in the psychological model, I hope here to display some of the evolution of his thoughtan evolution which displays an interesting constancy on certain themes.

$4 \quad$ See Phaedo 81A on elimination; see Phaedo 82C, 83B on turning from. While elimination and turning from are conceptually distinct I have put them together both because Plato seems not to distinguish them, and because their distinction doesn't greatly affect my present concerns.

$5 \quad$ See Phaedo 64D-E regarding the pleasures of food, drink, sex; sexual frenzy is assailed at Republic 402E-403A. Republic 605D-E deals with most of the other emotions above listed. At the very least he is urging their restriction, though it is possible to read this as an argument for their elimination through their withering.

6 For example, the Phaedo wants to extinguish the pleasures of the body, 'except insofar as one cannot do without them' (64E). The point seems to be that since the body is temporarily needed so are the passions which serve its continued existence. Still these passions have no intrinsic value; hence the philosopher turns away from them as much as possible.

7 The image of the horse being reigned in, whipped, etc. comes from the Phaedrus; mastery and ruling is appealed to in the Phaedo (80A, 82C); control and discipline, the Republic $8 \quad$ The suggestion seems to be that the place of wisdom (phronessis) has made the passions ineffective, rather than has eliminated them. Thus he also comments: 'whether pleasures and fears and all such things be present or absent.' (69B). I suggest that this is possible because the passions have been limited, and perhaps transformed-as the language of 'catharsis' may suggest. 9 Such is the upshot of our initial quotation, and the general view expressed in the N.E. There are some questionable cases. For example, so holding assumes that emotions such as envy can be treated excesses or defects of emotion rather than as independent and malignant emotions. 
See J.O. Urmson, 'Aristotle's Doctrine of the Mean,' collected Articles in Aristotle's Ethics, edited by A. Rorty (University of California Press, 1980) for a defense of this view. But if this is wrong, then because certain emotions are to be excluded, the contrast with Plato on this point is general, not universal.

10 Aristotle, then, is not simply allowing passions' presence but making that presence central to the analysis of excellence, as is action (cf. 1106B25-28).

An interesting puzzle becomes whether on the Aristotelian analysis there are situations of virtue in which the relevant feeling is not warranted and indeed is prohibited. The answer to this should shadow the possibility that there are like situations where action is not warranted and indeed is prohibited. Moreover, an answer would have to accommodate the opening quotation. In light of all this, I suggest that where the situation is described as a situation of virtue, and where the concern is the passion relevant to such situations, we should be moved. Not to be moved would be to fail.

11 In making way for strong passion I follow interpreters of the doctrine of the mean who stress that to hold to the mean does not necessitate moderation in all things (See Urmson (ibid) and J.L. Ackrill in Aristotle the Philosopher (Clarendon Press, 1980)). Thus it can be appropriate to be extremely, but never excessively, angry, fearful, etc.

12 Consider, for example, Aristotle's thoughts on the person in battle who hasn't time to think but must simply react (cf. 1117A15-24).

13 Consider, for example, N.E 2/4 in which Aristotle considers the factors beyond virtuous activity that are needed for virtue. He holds that the activity proceed from knowledge, that the actions be chosen for their own sake, and come from a firm unchanging character. The role of knowledge is said to be least important.

In relinquishing the control and dominance of reason Aristotle does not eliminate the possibility of struggle, as his account of continence displays. Generally, the objections Aristotle has to the Platonic picture concerns the philosophical classification or analysis of certain phenomena rather than objecting to the existence of such phenomena.

14 The notion of self is a useful way of focusing the point for us, but is not a principal concern for the Greeks. I infer it here on the following basis: death is the separation of body and soul, where intellect is closely associated with the soul, and desire, etc. closely associated with 
body (64C ff). Since one of Socrates' concerns is to argue for his survival, and since that is argued for in terms of the intellect and soul, the self seems to go with one's intellect.

15 The move from distinct to separate is made most famously and clearly by Hume in his Treatise I, pt.2, cf. I.III.III.

16 There is some ambiguity in the text. The main thrust of Plato's argument is directed towards the passions (primarily due to their bodily nature), but at times his attack seems to be on the bodily passions. The latter, but not the former, might legitimize certain passions (cf. $81 \mathrm{ff}$ ). I don't see that Plato has reconciled these two points of view in this work, but at times appeals to each.

17 One might argue that the very conception of philosophy is that of wisdom loving, and therefore, that very conception must undercut or soften what I have just written. It is certainly true that the place of 'philosophia' as well as love of learning (114E)-if not simply a linguistic hold over-requires that Plato can't hold the eliminative or limitation theses for all passions in all respects. To so conclude fits well with an earlier point that some of Plato' s remarks seem an attack on the passions of the body allowing for praise for passions of the soul. Still, I think it would be wrong to conclude that Plato's target or primary target is the bodily passions as opposed to the passions of the soul. For example, when speaking of the powers of the soul he does not praise the soul's fear, anger. See also 68Dff 65Cff, 81 A ff.

18 This observation speaks to the view that the passions are attributes of the body rather than the soul. It would have to be modified regarding those passages which suggest that Plato is concerned with the passions of the body as opposed to those of the soul. Here it would be that what is distinguished in terms of body and soul is conceived of as separated from one another, and that the distinction separation is oppositional in structure.

19 This kind of view is continued in the Protagoras in which the rational soul is said to be fit to command desire; so fit is it that it can't be overcome. While not well-developed, the model in the Meno's discussion of the possibility of incontinence (77Bff) offers a strikingly different conception.

20 The notion of character is very promising. Consider the following remark by Plato:

The man who has been properly nurtured.. . will praise beautiful things, rejoice in them, receive them in his soul, be nurtured by them and become both good and beautiful in 
character. He will rightly object to what is ugly and hate it while still young before he can grasp the reason, and when reason comes he who has been reared thus will welcome it and easily recognize it because of its kinship with himself. (Republic 402A)

21 I put it this way because the contrast between spirit and desire is in many ways unclear. I take it that some passions fall under the former (anger and probably fear) — but that most fall under the latter.

22 See 442A. Also, consider that it is right for the guardian to fear disgrace. Still, anger amongst guardians is not appropriate (378C-D), nor is fear appropriate to danger (386A-B). So, we seem not to have moved to Aristotle's attitude as expressed in the 'opening. Nevertheless the spirit of the Republic is more friendly to passions.

23 Plato's functional model (352D-4A) is reinforced by the principle of division for soul parts - where the division by parts is oppositional and exclusive (437ff).

24 For example, were Plato to have the parts 'reasoning' with one another, then reason would be cast both as a soul part yet employed in the operations beyond that part. But if so, Plato's understanding of the parts of the soul by principles of opposition and the metaphysics of function would have been undercut. Thus to the extent that Plato's part psychology is exhaustive, he is left unable to explain interrelation amongst the soul-and thereby quickly reverts to metaphors such as struggle, harmony, etc.

25 The claims of autonomous, utterly diverse parts sits best with the psychology developed in the early part of the Republic. The psychology in book 9 complicates matters in the sense that each functioning unit is said to have its own pleasure and desire. These complications, however, seem ad hoc, enabling Plato to generate particular arguments concerning happiness. The tripartite separate entity psychology remains in control, and fitting these later developments in with it seems hard to understand, putting that psychology under severe strain-as the previous notes indicates.

26 Plato's understanding of character whilst promising has not delivered. In effect, he incorporates within the idea of character features of the contrast he had earlier included in the soul-body contrast. For example, the virtue of moderation is a harmony created by the domination of reason, without rebellion (442D). Courage while having legitimized some fears remains dominated by the thought of preserving belief in the midst of pleasures and pains 
(442C). The desires are on the whole to be suppressed, etc

27 Here the emphasis is upon the non-necessary desires, which seems to encompass the bulk of our passions. Yet the necessary desires too remain to be held in line, well-ordered, lest they become ignoble (558Dff).

28 Here I restrict my gaze to the account of mortal creatures (cf. 413a30-33). Matters are different for the Gods.

29 In consequence looking for the self in the soul or a soul part is equally wrongheaded.

30 In a somewhat different context Aristotle returns to the contrast between convex and concave, claiming 'the two being different in definition but spatially inseparable.' (De An 433B24-5)

31 De An 433A31-b4 furthers this point. In Republic 9 Plato has seen the problem too.

Whereas Aristotle has drawn his analysis of the soul in light of it, Plato has tried (unsuccessfully, I suggest) to simply add the thought on to the account.

32 Not that Aristotle doesn't believe that the parts of the soul have a different nature, rather it is how the difference is understood that has changed.

33 Complexity here isn't a concern for more or less complex ways of doing the same thing, though - as we shall see - Aristotle has a concern for this too. Rather the notion of complexity at work here is a functional notion of intricate forms of life, where the more complex forms have more diverse means to discriminate and operate upon our world.

34 Both thinkers employ a functional analysis within the soul, but the nature of the functionalism differs. Plato's functionalism depends upon opposition, exclusivity, and empirical or quasi-empirical units; Aristotle's functionalism is augmented. by his hierarchical analysis. 35 Aristotle does not develop this as much as one might like, but see, for example, his discussion of the nourishment of life forms with a sense of touch, versus life forms with nous, versus life forms with the nutritive faculty only, and his discussion about definitions that follows (De An 414A32ff). See also the discussion of movement in respect of place animals with and without reason (432B7-434A21).

${ }^{36}$ Clearly, then, the possibility for final success of Aristotle's analysis relies .heavily on his doctrine of causation, or an analogous doctrine. 
I have suggested that in neither thinker do all their remarks conform to the analyses featured here. Two rather important departures by Aristotle should be noted. Most famously is Aristotle's exception for a separable intellect regarding contemplation (book 3). This shows Aristotle to be reverting to the quasi-empirical, part psychologizing of Plato-here driven by the 'like knows like' thesis in combination with the view that 'thinking thinks all things.' Again, Aristotle's speculations about the location of the soul seems to betray a Platonic part empiricism regarding the soul (ct. On Youth, Old Age, Life and Death and Respiration 469b1-20).

37 The argument, so far, establishes something about the passions as a whole. At times Aristotle seems interested to distinguish emotion from desire (See my 'Aristotle and the Emotions,' (Phronesis, no.2). It seems that the former is even more fully imbued by the rational. Aristotle, then, differentiates the extent to which a higher soul complicates the analysis of a lower.

A further complication here is to be seen in his denial that the vegetative soul 'shares in reason' (1102B29-30). While this denial regarding the vegetative may be taken to show that my remarks about the operations of the sexual-nutritive soul are misleading, it need not follow. I take Aristotle's use of 'share in reason' and 'listen to reason' to be terms of art, capturing the particular impact of the rational regarding the passions. Thus the remark about the vegetative not 'sharing of reason' does not dispute that the rational influences the vegetative. Moreover, I note that in his ethical works the vegetative soul is pretty much to be disregarded (cf. 1219B32). The ways and extent to which the higher souls affect the lower, and/or elements within the lower, then, is exceedingly complex. Here we have only an outline of that impact.

38 Not that intellect can't come to have something like that role in our life - as the continent and incontinent well know.

39 Its aptness rather than simple possibility seems to be based on the teleological framing of the passions in which they are seen to have their goods. 